\title{
Experimental Design and Response Surface Modeling for Optimization of 2-Chlorophenol Removal from Water by Nanoscale Iron and Fe Powder \\ Daraei $\mathrm{H}^{1 *}$ and Kamali $\mathrm{H}^{2}$
}

${ }^{1}$ Department of Environmental Health Engineering, Shahid Beheshti University of Medical Sciences, Tehran, Iran

${ }^{2}$ Research Center of Natural Product Safety and Medicinal Plants, North Khorasan University of Medical Sciences, Bojnurd, Iran

\begin{abstract}
The discharge of organic contaminants such as phenol and its derivatives emerging from the industries into water has become a critical concern. In present research, potential of nanoscale iron particle and iron powder has been tested for the removal of 2-chlorophenol from aqueous solutions. In this research, nano particles were procreated by reduction of ferric iron in presence of sodium borohydrid. The characterization of synthesized particles was carried out using SEM and XRD analysis. The effect of $\mathrm{pH}$, initial concentration of chlorophenol, and contact time and sorbents dosage on 2-CP removal was investigated. A statistical experimental design based on "central composite design" was exerted for measure the effect of these variables. The results of the CCD predicted that the maximum adsorption of 2-CP (100\%) by $\mathrm{nZVI}$ could be achieved at $\mathrm{pH}$, initial concentration, time, and dosage of sorbent as $4,5.0 \mathrm{mg} / \mathrm{L}, 70 \mathrm{~min}$, and $1.33 \mathrm{~g}$, respectively. Also, for $86.74 \%$ removal of $2-\mathrm{CP}$, initial concentration, $\mathrm{pH}$, contact time and Fe powder dosage were 5.0 $\mathrm{mg} / \mathrm{L}, 3.23,56.92 \mathrm{~min}$ and $2.50 \mathrm{~g}$ respectively.
\end{abstract}

The results show that the $\mathrm{nZVI}$ can be applied for treatment of organic contaminants in water and wastewater. Also, the optimum conditions of these theoretically obtained variables are beneficial for their monitoring which can be applied at an industrial-scale process.

Keywords: Nano scale iron particle; 2-Chlorophenol; Central composite design; Powder; Potential

\section{Introduction}

Phenol and compound phenolic are one of the organic and priority pollutants amongst all industrial effluents. 2-chlorophenol is one of the derivatives for phenol which is produced during chlorination of water. This compound is the most toxic form of phenol, which imposes hazardous health effects towards humans as well as animals [1]. Chlorophenols are identified from aspects such as taste, smell, color and harmful to organisms. Also, Chlorophenols are corrosive compound for skin, eye and respiratory tract. Chlorophenols are rapidly absorbed when swallowed by the oral or respiration $[2,3]$. This organic pollutant accumulates mostly in the liver and kidney, muscle and brain. Chlorophenols are eliminated primarily in the urine as both free and bound forms, with lesser amounts in fecal matter. Also, these contaminants exist in the effluents of industrial, such as petroleum, plastics manufacturing, coal conversion, etc. Unfortunately, chlorophenol compounds are not desirous to biodegradation [4]. Different methods are employed for removal of Chlorophenols including chemical oxidation, adsorption, solvent extraction, reverse osmosis [5,6]. Despite these fruitful attempts, there is still a need to search a drastic matter to eradicate the menace of phenolic compound from wastewater and, hence it is envisaged to develop a systematic and exhaustive process for the removal of pollutants $[7,8]$. In present research, nano particle iron and iron powder were selected to investigate the optimum adsorption parameters for maximum removal of 2-chlorophenol from wastewater through batch adsorption process.

Literature survey reveals that in recent past nZVI has been successfully employed as an adsorbent for the removal of organic matters and metal ions from industrial effluents [8-10]. During recent years, the synthesis of nanoparticle Iron is of specific interest for researcher. NZVI and Fe powder are widely investigated in degradation of phenol and other organic matter [11]. These compounds can degrade contaminants in the short time than biodegradation under the same conditions [12]. Degradation of contaminants occurs on the surface of nZVI or Fe powder [13]. There are many ways to produce nanoparticles which one of these methods synthesizes ZVI nanoparticles by dropping ferric ion solution to borohydride solution [14]. In most of researches, the particles perform best when the size is typically around 1-100 nm $[15,16]$. The purpose of this research was to synthesize of nanoscale iron particle by a cheap method and comparison of its efficiency with Fe powder.

The purpose of the present study is to investigate the optimum conditions for the removal of 2-chlophenol from aqueous solutions using nZVI and Fe powder. This paper includes results on the effects of $\mathrm{pH}$, temperature, contact time, sorbent dosage, and 2-chlorophenol concentration. Another prominent feature of the present paper is application of the gathered data on statistical calculations based on "Central Composite Design (CCD)" and theoretical monitoring of effects of various operating variables such as $\mathrm{pH}$, sorbent dosage, and 2-chlorophenol concentration on the performance of the sorption process.

\section{Material and Methods}

\section{Preparation of the nZVI}

In this research, nano particles were procreated by reduction of ferric iron in the presence of sodium borohydrid. These particles synthesized with 1:1 volume ratio of $\mathrm{NaBH}_{4}$ and $\mathrm{FeCl}_{3} \cdot 6 \mathrm{H}_{2} \mathrm{O}$. The nano particles were produced each day. $\mathrm{NaBH}_{4}$ solution $(0.16 \mathrm{M})$ added drop into $\mathrm{FeCl}_{3} \cdot 6 \mathrm{H}_{2} \mathrm{O}(0.1 \mathrm{M})$ by vigorous magnetic stirring at atmospheric

*Corresponding author: Daraei H, Department of Environmental Health Engineering, Shahid Beheshti University of Medical Sciences, Tehran, Iran, Tel: 021-22-432-040; E-mail: H.daraei@sbmu.ac.ir

Received April 21, 2014; Accepted May 28, 2014; Published June 02, 2014

Citation: Daraei H, Kamali H (2014) Experimental Design and Response Surface Modeling for Optimization of 2-Chlorophenol Removal from Water by Nanoscale Iron and Fe Powder. J Environ Anal Toxicol 4: 228. doi: 10.4172/2161-0525.1000228

Copyright: $\odot 2014$ Daraei $\mathrm{H}$, et al. This is an open-access article distributed under the terms of the Creative Commons Attribution License, which permits unrestricted use, distribution, and reproduction in any medium, provided the original author and source are credited. 
conditions during 1 hour. Finally, fine black precipitates created and precipitated according to the following reaction:

$$
2 \mathrm{FeCl}_{3}+6 \mathrm{NaBH}_{4}^{-}+18 \mathrm{H}_{2} \mathrm{O} \rightarrow 2 \mathrm{Fe}_{(s)}^{0}+6 \mathrm{~B}(\mathrm{OH})_{3}+21 \mathrm{H}_{2}+6 \mathrm{NaCl}
$$

\section{Chemicals and batch experimental}

All chemicals were procured from $\mathrm{M} / \mathrm{s}$ Merk. Standard 2-chlorophenol (2CP) stock solution was prepared and all working solutions were prepared by diluting the stock solution. Experiment was done at different qualification of contact time $(10,40,70,100$ and 130 $\mathrm{min})$, phenol concentration $(5,10,15,20$ and $25 \mathrm{mg} / \mathrm{L}), \mathrm{pH}(2,4,6$, 8 and 10$)$, temperature $\left(20,30,40,50\right.$ and $\left.60^{\circ} \mathrm{C}\right)$ and sorbent dosage $(0.5,1.5,2.5,3.5$ and $4.5 \mathrm{~g})$. The concentration of residual phenol was determined using the spectrophotometer DR-5000 in $\lambda_{\max }=520$ $\mathrm{nm}$. Also for data analysis the Response Surface Method was used. The central composite design was applied to appraisal the effect of

\begin{tabular}{|l|c|c|c|c|c|}
\hline \multirow{2}{*}{ Independent variables } & \multicolumn{5}{|c|}{ Levels } \\
\cline { 2 - 6 } & $+\alpha^{\mathrm{a}}$ & 1 & 0 & -1 & $-\alpha a$ \\
\hline initial concentration (mg/L) & 45 & 35 & 25 & 15 & 5 \\
\hline pH & 10 & 8 & 6 & 4 & 2 \\
\hline time (min) & 85 & 65 & 45 & 25 & 5 \\
\hline Dosage (g) & 2.5 & 2.0 & 1.5 & 1.0 & 0.5 \\
\hline
\end{tabular}

${ }^{\mathrm{a}} \alpha=2$, calculated by Minitab software

Table 1: Range of Values of Central Composite Design.

\begin{tabular}{|c|c|c|c|c|c|c|}
\hline Run & $\begin{array}{c}\text { 2-CP } \\
\text { concentration } \\
(\mathrm{mg} / \mathrm{L})\end{array}$ & $\mathrm{pH}$ & Time(min) & Dosage(g) & $\begin{array}{l}\text { Observed } \\
\text { Yield (\%) }\end{array}$ & $\begin{array}{l}\text { Predicted } \\
\text { Yield (\%) }\end{array}$ \\
\hline 1 & 15 & 4 & 25 & 1.0 & 73.70 & 72.0796 \\
\hline 2 & 35 & 4 & 25 & 1.0 & 67.80 & 67.0275 \\
\hline 3 & 15 & 8 & 25 & 1.0 & 38.32 & 38.4075 \\
\hline 4 & 35 & 8 & 25 & 1.0 & 38.90 & 39.5879 \\
\hline 5 & 15 & 4 & 65 & 1.0 & 86.40 & 84.7275 \\
\hline 6 & 35 & 4 & 65 & 1.0 & 73.30 & 72.5679 \\
\hline 7 & 15 & 8 & 65 & 1.0 & 52.20 & 52.9379 \\
\hline 8 & 35 & 8 & 65 & 1.0 & 47.15 & 47.0108 \\
\hline 9 & 15 & 4 & 25 & 2.0 & 90.70 & 89.9942 \\
\hline 10 & 35 & 4 & 25 & 2.0 & 76.90 & 74.9096 \\
\hline 11 & 15 & 8 & 25 & 2.0 & 47.60 & 47.0796 \\
\hline 12 & 35 & 8 & 25 & 2.0 & 37.40 & 38.2275 \\
\hline 13 & 15 & 4 & 65 & 2.0 & 100.00 & 98.0596 \\
\hline 14 & 35 & 4 & 65 & 2.0 & 76.80 & 75.8675 \\
\hline 15 & 15 & 8 & 65 & 2.0 & 57.10 & 57.0275 \\
\hline 16 & 35 & 8 & 65 & 2.0 & 40.70 & 41.0679 \\
\hline 17 & 5 & 6 & 45 & 1.5 & 83.40 & 85.2046 \\
\hline 18 & 45 & 6 & 45 & 1.5 & 63.90 & 64.1929 \\
\hline 19 & 25 & 2 & 45 & 1.5 & 68.30 & 72.4346 \\
\hline 20 & 25 & 10 & 45 & 1.5 & 6.00 & 3.9629 \\
\hline 21 & 25 & 6 & 5 & 1.5 & 55.00 & 55.9546 \\
\hline 22 & 25 & 6 & 85 & 1.5 & 70.30 & 71.4429 \\
\hline 23 & 25 & 6 & 45 & 0.5 & 65.90 & 66.5629 \\
\hline 24 & 25 & 6 & 45 & 2.5 & 77.10 & 78.5346 \\
\hline 25 & 25 & 6 & 45 & 1.5 & 70.40 & 70.7000 \\
\hline 26 & 25 & 6 & 45 & 1.5 & 70.80 & 70.7000 \\
\hline 27 & 25 & 6 & 45 & 1.5 & 71.00 & 70.7000 \\
\hline 28 & 25 & 6 & 45 & 1.5 & 70.50 & 70.7000 \\
\hline 29 & 25 & 6 & 45 & 1.5 & 70.70 & 70.7000 \\
\hline 30 & 25 & 6 & 45 & 1.5 & 70.90 & 70.7000 \\
\hline 31 & 25 & 6 & 45 & 1.5 & 70.60 & 70.7000 \\
\hline
\end{tabular}

Table 2: Theoretically Predicted Values of Percentage Removal of 2-CP by $n Z V I$ for the Different Selected Levels of Variables. operating variables such as $\mathrm{pH}$, sorbent dosage, and 2-chlorophenol concentration on the performance of the sorption process. Thus, for investigation the interactive influence of these independent parameters and their optimization for 2-chlorophenol biosorption process Response Surface Methodology (RSM) was applied.

\section{Experimental design}

A statistical experimental design based on "Central Composite Design (CCD)" was planned [17] and the percentage removal of 2-chlorophenol was measured for different variables such as $\mathrm{pH}, 2 \mathrm{CP}$ concentration, time and dosage of nZVI and Fe powder abbreviated as $\mathrm{x} 1, \mathrm{x} 2, \mathrm{x} 3, \mathrm{x} 4$, and $\mathrm{x} 5$, respectively. These variables were investigated at five levels $(-2,-1,0,1,2)$ and the dependent variable was chosen as Y. In present study, Minitab software package was used to design and evaluate these five independent variables at five levels on the responses according to the Eq. (2). The ranges for the selected levels of the five variables are shown in Table 1, while the experimental percentage removal of 2-CP for different selected levels of these variables is presented in Tables 2 and 3 for all the 30 runs carried out during the theoretical treatment.

$$
Y=\beta_{0}+\sum \beta_{j} \cdot X_{i}+\sum \beta_{j j} \cdot X_{j}^{2}+\sum \beta_{j k} \cdot X_{j} \cdot X_{k}
$$

Where, $Y=$ response, $\beta_{0}=$ intercept, $\beta_{j}=$ linear coefficients, $\beta_{i j}=$ squared coefficients, $\beta_{j k}=$ interaction coefficients, $X_{i}, X_{j 2}, X_{j}, X_{k}=$ level of independent variables.

Moreover, the theoretically predicted values of yield at different experimental conditions are illustrated in Tables 2 and 3.

\section{Results and Discussions}

\section{Characterization of $\mathrm{nZVI}$}

Properties of nano iron particles were determined with scanning electron microscope (SEM) and X-Ray Diffractometry (XRD). The morphology of nZVI was ascertained with the help of scanning electron microscopy (SEM) analysis. These analyses show the quantitative characteristics such as the particle size, shape/morphology and surface area of the particles. Figure 1 exhibits the SEM images of the synthesized nano particle. It is determined that nanoscale Iron particles can have several good advantages such as high specific surface, great surface reactivity and flexibility in applications [18]. The results display that the nano scale particles are some deal spherical. The result shows that these spherical particles have thread-like structures. This property increased the available and specific surfaces for more reaction.

The XRD pattern (Figure 2) displays six characteristic peaks at $2 \theta=$ $4.4521^{\circ}, 16.54^{\circ}, 31.5378^{\circ}, 44.2876^{\circ}, 57.6486^{\circ}$ and $71.4737^{\circ}$ in crystalline structure and corroborates the presence of Lepidocrocite $\left(\mathrm{Fe}^{+3} \mathrm{O}(\mathrm{OH})\right)$ in the nZVI.

\section{Theoretical treatment for deriving optimum conditions}

The experimental results represent that the maximum adsorption of 2-CP (100\%) by nZVI could be achieved at $\mathrm{pH}$, initial concentration, time, and dosage of sorbent as $4,5.0 \mathrm{mg} / \mathrm{L}, 70 \mathrm{~min}$, and $1.33 \mathrm{~g}$, respectively. Also, for maximum removal of 2-CP (86.74\%), concentration, $\mathrm{pH}$, time, and dosage were $5.0 \mathrm{mg} / \mathrm{L}, 3.23,56.92 \mathrm{~min}$, and $2.50 \mathrm{~g}$, respectively. The optimum conditions of these variables obtained theoretically were used to monitoring them, which can be applied to an industrial-scale process.

Following second-order polynomial equation is proposed for the prediction of percentage removal of 2-CP as a function of different variables [17]. 
Citation: Daraei H, Kamali H (2014) Experimental Design and Response Surface Modeling for Optimization of 2-Chlorophenol Removal from Water by Nanoscale Iron and Fe Powder. J Environ Anal Toxicol 4: 228. doi: 10.4172/2161-0525.1000228

Page 3 of 6

$Y=70.70-5.2529 C_{c p}-17.1179 p H+3.8721 t+2.9929 D_{n Z V I}+$ $0.9997 C_{c p}{ }^{2}-8.1253 p H^{2}-1.70503 t^{2}+1.5581 p H \times C_{c p}-1.7769 C_{c p} \times t$ $-2.5081 C_{c p} \times D_{n Z V I}-2.3106 p H \times D_{n Z V I}-1.1456 t \times D_{n Z V I}$

\begin{tabular}{|c|c|c|c|c|c|c|}
\hline Run & $\begin{array}{c}\text { 2-CP } \\
\text { concentration } \\
(\mathrm{mg} / \mathrm{L})\end{array}$ & pH & Time(min) & Dosage(g) & $\begin{array}{l}\text { Observed } \\
\text { Yield (\%) }\end{array}$ & $\begin{array}{l}\text { Predicted } \\
\text { Yield }(\%)\end{array}$ \\
\hline 1 & 15 & 4 & 25 & 1.0 & 51.60 & 50.4596 \\
\hline 2 & 35 & 4 & 25 & 1.0 & 47.46 & 46.9304 \\
\hline 3 & 15 & 8 & 25 & 1.0 & 26.82 & 26.8804 \\
\hline 4 & 35 & 8 & 25 & 1.0 & 27.23 & 27.7063 \\
\hline 5 & 15 & 4 & 65 & 1.0 & 60.48 & 59.3071 \\
\hline 6 & 35 & 4 & 65 & 1.0 & 51.31 & 50.7929 \\
\hline 7 & 15 & 8 & 65 & 1.0 & 36.54 & 37.0629 \\
\hline 8 & 35 & 8 & 65 & 1.0 & 33.00 & 32.9038 \\
\hline 9 & 15 & 4 & 25 & 2.0 & 63.50 & 63.0021 \\
\hline 10 & 35 & 4 & 25 & 2.0 & 53.85 & 52.4479 \\
\hline 11 & 15 & 8 & 25 & 2.0 & 33.32 & 32.9579 \\
\hline 12 & 35 & 8 & 25 & 2.0 & 26.18 & 26.7588 \\
\hline 13 & 15 & 4 & 65 & 2.0 & 70.00 & 68.6446 \\
\hline 14 & 35 & 4 & 65 & 2.0 & 53.76 & 53.1054 \\
\hline 15 & 15 & 8 & 65 & 2.0 & 40.00 & 39.9354 \\
\hline 16 & 35 & 8 & 65 & 2.0 & 28.49 & 28.7513 \\
\hline 17 & 5 & 6 & 45 & 1.5 & 58.38 & 59.6483 \\
\hline 18 & 45 & 6 & 45 & 1.5 & 44.73 & 44.9350 \\
\hline 19 & 25 & 2 & 45 & 1.5 & 47.81 & 50.7083 \\
\hline 20 & 25 & 10 & 45 & 1.5 & 4.20 & 2.7750 \\
\hline 21 & 25 & 6 & 5 & 1.5 & 38.50 & 39.1717 \\
\hline 22 & 25 & 6 & 85 & 1.5 & 49.21 & 50.0117 \\
\hline 23 & 25 & 6 & 45 & 0.5 & 46.13 & 46.5917 \\
\hline 24 & 25 & 6 & 45 & 2.5 & 53.97 & 54.9817 \\
\hline 25 & 25 & 6 & 45 & 1.5 & 49.28 & 49.5143 \\
\hline 26 & 25 & 6 & 45 & 1.5 & 49.60 & 49.5143 \\
\hline 27 & 25 & 6 & 45 & 1.5 & 49.70 & 49.5143 \\
\hline 28 & 25 & 6 & 45 & 1.5 & 49.40 & 49.5143 \\
\hline 29 & 25 & 6 & 45 & 1.5 & 49.50 & 49.5143 \\
\hline 30 & 25 & 6 & 45 & 1.5 & 49.65 & 49.5143 \\
\hline 31 & 25 & 6 & 45 & 1.5 & 49.47 & 49.5143 \\
\hline
\end{tabular}

Table 3: Theoretically Predicted Values of Percentage Removal of 2-CP by Fe powder for the Different Selected Levels of Variables.
$Y=49.5143-3.6783 C_{c p}-11.9833 p H+2.7100 t+2.0975 D_{F e}+$ $0.6943 C_{c p}^{2}-5.6932 p H^{2}-1.2307 t^{2}+1.0888 p H \times C_{c p}-1.2462 C_{c p} \times t$ $-1.7562 C_{c p}^{c p} \times D_{F e}-1.6163 p H \times D_{F e}-0.8013 t \times D_{F e}$

$\mathrm{T}=$ temperature, $\mathrm{P}=\mathrm{pH}, \mathrm{C}_{\mathrm{cp}}=2-\mathrm{CP}$ concentration, $\mathrm{t}=$ time, and $\mathrm{D}=$ dosage of adsorbent.

The obtained response surface model from an experimental design was evaluated using ANOVA and analysis of residuals was performed. The results of the statistical analyses include the estimated regression coefficients; t-test and p-values of the sorption are tabulated in Tables 4 and 5 . The regression coefficient $\left(\mathrm{R}^{2}\right)$ adjusted of the sorption was found close to unity, which indicates that the developed models is able to fully predict the percentage removal of 2-CP. The linear regression coefficient of the sorption was also found as 0.9956 , which shows good performance of the model on the experimentally observed as well as theoretically predicted percentage of 2-CP removal.

Tables 4 and 5 exhibits that larger the $t$-value and the smaller the p-value, the more significant is the corresponding coefficient. Based on the statistical results (ANOVA) with confidence level of 95\%, the effect of each term in the models could be significant provided that its $\mathrm{p}$-value is smaller than 0.05 (p-value $<0.05$ ) [19].

\section{Variables affecting}

The effect of the 2-CP concentration and $\mathbf{p H}$ : Figures 3 and 4 exhibit that by increasing the 2-Chlorophenol concentration a decrease in the percentage removal of this compound sorption is observable and maximum sorption (100 and $87.74 \%$ ) was predicted at $5.0 \mathrm{mg} / \mathrm{L}$ 2-CP concentration with nZVI and Fe powder, respectively. The initial concentration was $5,15,25,35$ and $45 \mathrm{mg} / \mathrm{L}$. Initial concentration of contaminant is a main agent for efficiency of Fe particles. According to the results, with the initial 2-CP concentration increase, the degradation efficiency decreased. The results show that the reaction time for the further degradation of 2-CP extended with increase in initial 2-CP concentration. With increase in 2-CP concentration, this organic contaminant molecules can be adsorbed on the reactive surface of iron particles and these ions can be occupy greater number of active sites on the particle surface [20]. Thus, at lower concentration, large number of pores on the sorbent surface was available for reaction. Then, the pore sites on the surface became occupied by 2-CP molecules and
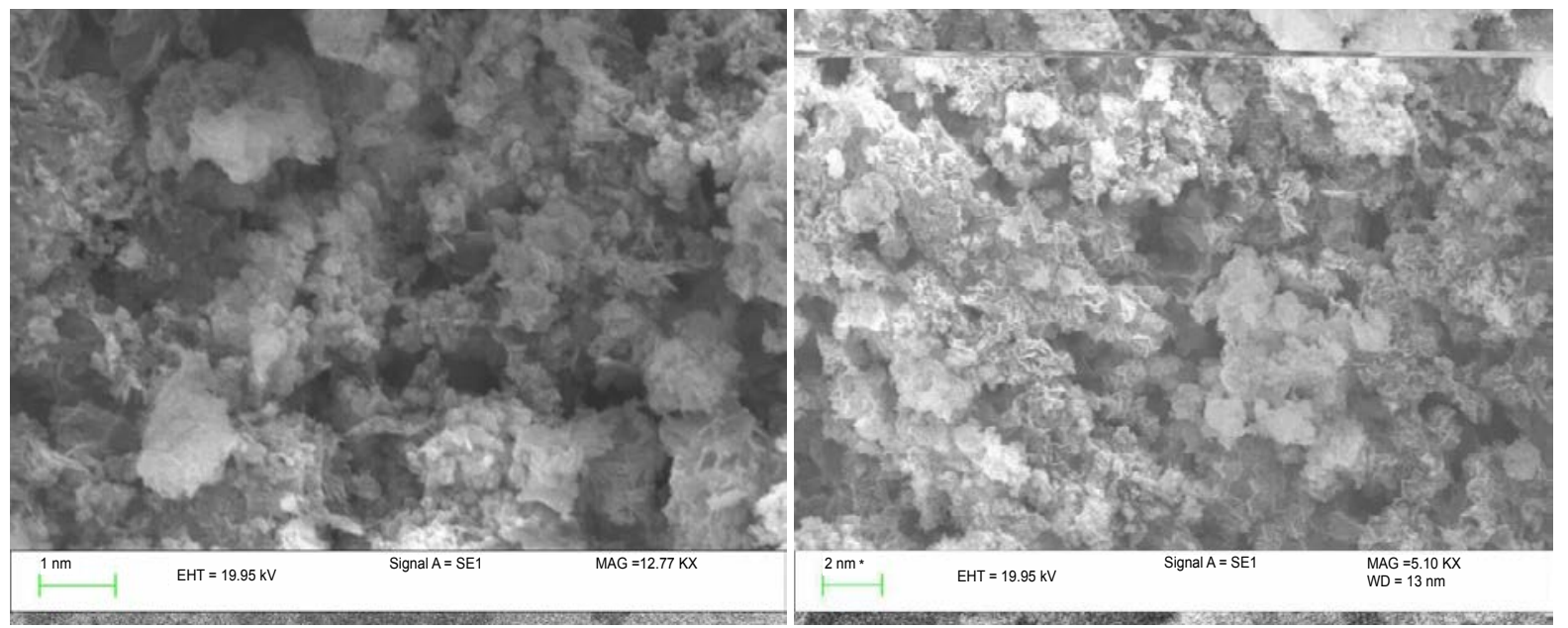

Figure 1: SEM images of nano zero valent iron paricle. 


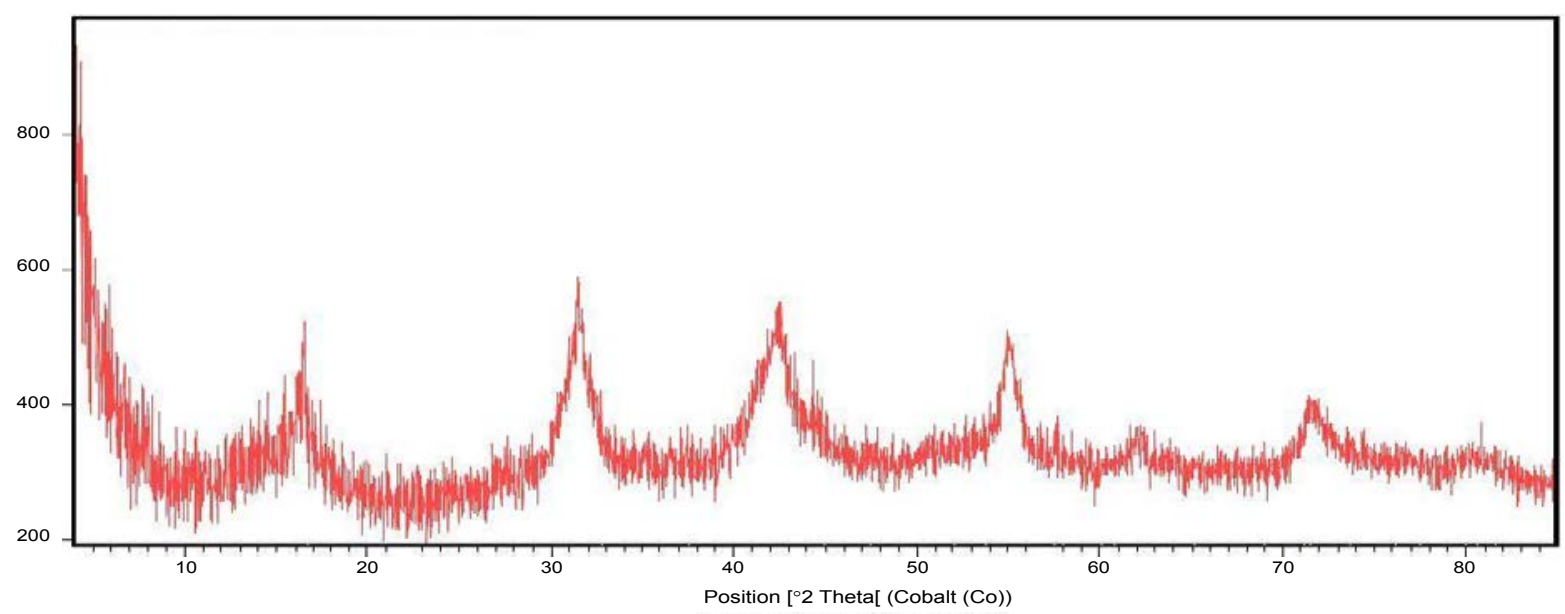

Figure 2: X-ray Diffraction Pattern of nano zero valent iron particles.

\begin{tabular}{|c|c|c|c|}
\hline Term & Regression coefficients & $\boldsymbol{t}$-value & $\boldsymbol{p}$-value \\
\hline Constant & 70.7000 & 108.708 & 0.000 \\
\hline $\mathrm{C}_{\mathrm{cp}}(\mathrm{mg} / \mathrm{L})$ & -5.2529 & -14.955 & 0.000 \\
\hline $\mathrm{pH}$ & -17.1179 & -46.736 & 0.000 \\
\hline $\mathrm{t}(\mathrm{min})$ & 3.8721 & 11.024 & 0.000 \\
\hline $\mathrm{D}(\mathrm{g})$ & 2.9929 & 8.521 & 0.000 \\
\hline $\mathrm{C}_{\mathrm{cp}}{ }^{2}(\mathrm{mg} / \mathrm{L})^{2}$ & 0.9997 & 3.107 & 0.007 \\
\hline $\mathrm{pH}{ }^{2}$ & -8.1253 & -25.251 & 0.000 \\
\hline $\mathrm{t}^{2}(\mathrm{~min})^{2}$ & -1.7503 & -5.440 & 0.000 \\
\hline $\mathrm{D}^{2}(\mathrm{~g})^{2}$ & 0.4622 & 1.436 & 0.170 \\
\hline $\mathrm{pH} \times \mathrm{C}_{\mathrm{cp}}(\mathrm{mg} / \mathrm{L})$ & 1.5581 & 3.622 & 0.002 \\
\hline $\mathrm{C}_{\mathrm{cp}}(\mathrm{mg} / \mathrm{L}) \times \mathrm{t}(\mathrm{min})$ & -1.7769 & -4.131 & 0.001 \\
\hline $\mathrm{C}_{\mathrm{cp}}(\mathrm{mg} / \mathrm{L}) \times \mathrm{D}(\mathrm{g})$ & -2.5081 & -5.830 & 0.000 \\
\hline $\mathrm{pH} \times \mathrm{t}(\mathrm{min})$ & 0.4706 & 1.094 & 0.290 \\
\hline $\mathrm{pH} \times \mathrm{D}(\mathrm{g})$ & -1.8787 & -5.371 & 0.000 \\
\hline $\mathrm{t}(\mathrm{min}) \times \mathrm{D}(\mathrm{g})$ & -1.1456 & -2.663 & 0.017 \\
\hline
\end{tabular}

Table 4: Observed Regression Coefficients, t-Test, and p-Values for 2-CP remova by $n Z V I$.

\begin{tabular}{|c|c|c|c|}
\hline Term & Regression coefficients & $\boldsymbol{t}$-value & $\boldsymbol{p}$-value \\
\hline Constant & 49.5143 & 108.708 & 0.000 \\
\hline $\mathrm{C}_{\mathrm{cp}}(\mathrm{mg} / \mathrm{L})$ & -3.6783 & -14.933 & 0.000 \\
\hline $\mathrm{pH}$ & -11.9833 & -48.651 & 0.000 \\
\hline $\mathrm{t}(\mathrm{min})$ & 2.7100 & 11.002 & 0.000 \\
\hline $\mathrm{D}(\mathrm{g})$ & 2.0975 & 8.516 & 0.000 \\
\hline $\mathrm{C}_{\mathrm{cp}}{ }^{2}(\mathrm{mg} / \mathrm{L})^{2}$ & 0.6943 & 3.077 & 0.007 \\
\hline $\mathrm{pH}$ & -5.6932 & -25.229 & 0.000 \\
\hline $\mathrm{t}^{2}(\mathrm{~min})^{2}$ & -1.2307 & -5.454 & 0.000 \\
\hline $\mathrm{D}^{2}(\mathrm{~g})^{2}$ & 0.3181 & 1.410 & 0.178 \\
\hline $\mathrm{pH} \times \mathrm{C}_{\mathrm{cp}}(\mathrm{mg} / \mathrm{L})$ & 1.0888 & 3.609 & 0.002 \\
\hline $\mathrm{C}_{\mathrm{cp}}(\mathrm{mg} / \mathrm{L}) \times \mathrm{t}(\mathrm{min})$ & -1.2462 & -4.131 & 0.001 \\
\hline $\mathrm{C}_{\mathrm{cp}}(\mathrm{mg} / \mathrm{L}) \times \mathrm{D}(\mathrm{g})$ & -1.7562 & -5.822 & 0.000 \\
\hline $\mathrm{pH} \times \mathrm{t}(\mathrm{min})$ & 0.3338 & 1.106 & 0.285 \\
\hline $\mathrm{pH} \times \mathrm{D}(\mathrm{g})$ & -1.6163 & -5.358 & 0.000 \\
\hline $\mathrm{t}(\mathrm{min}) \times \mathrm{D}(\mathrm{g})$ & -0.8013 & -2.656 & 0.017 \\
\hline
\end{tabular}

Table 5: Observed Regression Coefficients, t-Test, and $\mathrm{p}$-Values for 2-CP remova by Fe powder.

efficiency decreased [21]. The decrease in percentage of adsorption at higher concentration is mainly due to unavailability of sorption sites at the sorbent for larger number of adsorbing 2-CP ions. Usually, surface atoms/ or ions, particularly atoms at border of nano particle iron, has a high activity in chemical reaction with contaminants. On the other hand, these atoms/or ions are reactive, active and available sites of sorbents surface [22]. Therefore, at the first stage 2-CP Molecules were adsorbed by these sites on the nanoscale surface, and the concentration of 2-CP decreased. Subsequently, some of the adsorbed these molecules reacted with the surface atoms of Fe particle [22]. In conclusion, the decrease of 2-CP molecules were the result of both sorption and degradation processes, and the initial concentration of 2,4-DCP also influenced adsorption process.

The effects of $\mathrm{pH}$ (2-10) and initial 2-chlorophenol concentration (5-45 mg/L) on the adsorption of 2-CP over nZVI and Fe powder were simultaneously monitored at removal efficiency and presented in Figures 3 and 4 . The $\mathrm{pH}$ of the solution was adjusted using $0.1 \mathrm{M} \mathrm{HCl}$ and $0.1 \mathrm{M} \mathrm{NaOH}$.

As results demonstrated, acidic conditions were more idealistic for removal of 2-CP and efficiency decreased when $\mathrm{pH}$ was greater than 4 and 3.23. Most of the organic contaminants were reduced effectively at lower $\mathrm{pH}$ values in the nZVI-water system since reduced function of nZVI under acidic conditions [23]. Also, $\mathrm{pH}$ may be affected in the mechanisms of the nZVI oxidative degradation. The results also display that the tendency and static traction between the 2-CP and nZVI/ and $\mathrm{Fe}$ powder meliorated at lower $\mathrm{pH}$, thus 2-CP could be adsorbed onto the Fe particles surface more easily. At alkaline condition, iron is converted to insoluble forms (ferrous hydroxide). These precipitations impose on the iron surface and the mass transfer is limited. Thus, 2-CP degradation is reduced. In alkaline conditions, 2-CP and Fe particles are negatively charged, thus this phenomenon is causing repulsive forces between phenoxide ion and $\mathrm{Fe}$ (III)-O- groups [24]. In addition, with $\mathrm{pH}$ increase, electrostatic repulsive force becomes operative, which thereby retards diffusion and adsorption.

In alkaline conditions, Iron ions are produced in solution. Then, the hydroxyl ion collided with Fe particles surface and ferrous ions dissolved in surface. Therefore, ferrous hydroxide produced in this reaction and precipitated on the iron surface. These precipitations occupy the available and active sites on the particles surface to hinder the repercussion. Also, at high $\mathrm{pH}$ nZVI surface is negative (Fe(III)-O-) electrostatic repulsive force becomes operative.

On the other hand, at acidic conditions is done acid washing on 


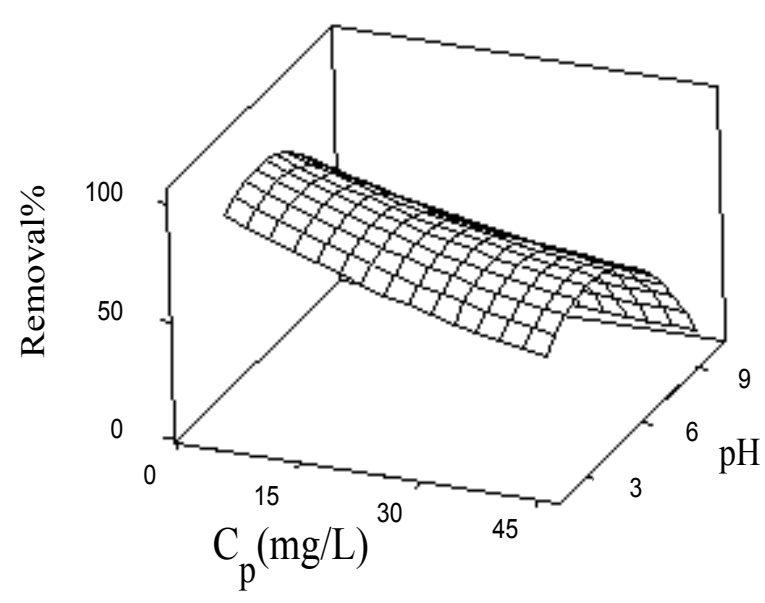

Figure 3: Response Surface of the Percentage Sorption of 2-CP ions versus $\mathrm{pH}$ and initial concentration by $\mathrm{nZVI}$.

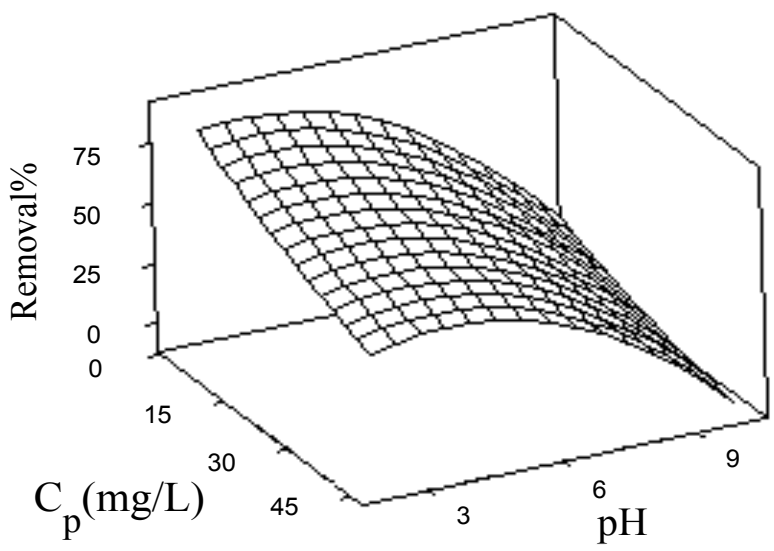

Figure 4: Response Surface of the Percentage Sorption of 2-CP ions versus $\mathrm{pH}$ and initial concentration by Fe powder.

metallic surfaces, broadly. These reactions, reduces passivation of $\mathrm{Fe}$ particles and metallic surfaces with Facilitating solvability of these hydroxides [25]. This is evidence that the degradation/or adsorption reduction of 2-CP with Fe particles is idealistic in lower $\mathrm{pH}$. Moreover, at low $\mathrm{pH}$, Iron particles have positive charge. These positive charges absorb ionized species of phenol and chlorophenol which has negative charges. Also, chlorophenol compounds known as proton donor. Therefore, removal of this compound in alkaline $\mathrm{pH}$ decreases due to the repulsive forces between negative groups $\left(\mathrm{Fe}^{+3}-\mathrm{O}^{-}\right)$and ions phenoxide. In this research, the p-value is used to determine the effect of each parameter. To prove the correctness of the parameters, the p-value should be less than 0.05 . The impact parameters is omitted if p-value is greater than 0.05 . ANOVA statistical test shows that there was no statistically significant difference between the removal efficiency and these variables ( $\mathrm{p}$-value $<0 / 05)$.

\section{The effect of contact time and dosage nZVI/Fe powder}

Removal efficiency for 2-CP at contact time of 5-85 min was investigated. The result showed that the optimum time for 2-CP removal by nZVI and Fe powder were obtained in $70 \mathrm{~min}$ and 56.92 min, respectively. Therefore, the 2-CP adsorption was found to increase with increase in time as shown in Figures 5 and 6. The 2-chlorophenol sorption in mentioned time was attributed to the surface junction between active surface groups and phenol ion. Also, the further sorption at the described times can be illustrated with an increased availability in the active bounding sites on the sorbent surface area [26,27].

As shown in Figures 5 and 6, when the Fe particles dosage increased, the removal efficiency increased. The reactivity of organic contaminants with Fe particles is relevant to the dosage of these particles. Usually, the reduction of chlorinated organic pollutants with iron particles is a surface function. Consequently, the removal of organic compounds such as 2-Chlorophenol by nZVI or Fe powder implicates direct contact between the organic matter and reactive parts on the iron particle surface. Chlorophenol may be eliminated as follows: In the first stages, the chlorophenol ions pervade through the solution to the sorbent surface, where these contaminants adsorb onto the reactive parts. Secondly, electrons are transferred from ZVI to the CP ions and produce a solution with lesser contaminants and various oxides on the surface [28]. Batch studies prove that the process of demolition of 2-CP consists sorption, dechlorination and cleavage and also precipitation [29]. Adsorption process includes agglomeration of the 2-CP ions

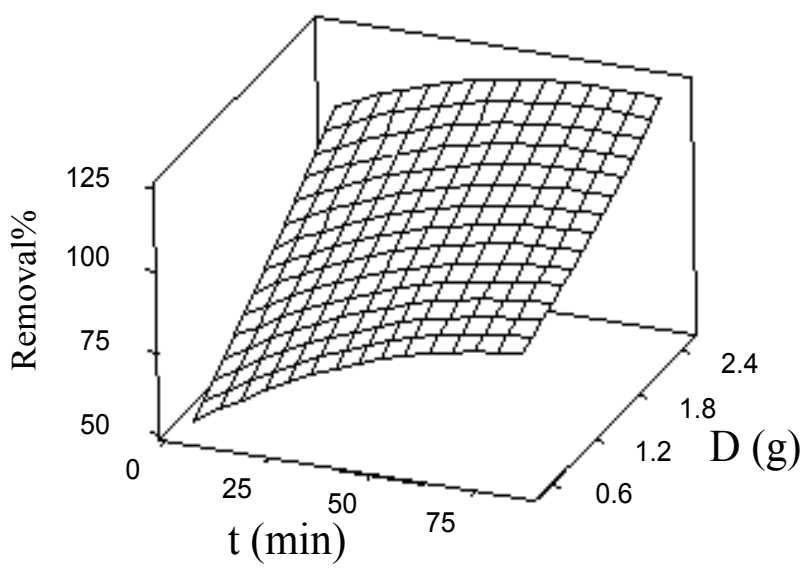

Figure 5: Response Surface of the Percentage Sorption of 2-CP ions versus time and dosage of $\mathrm{nZVI}$.

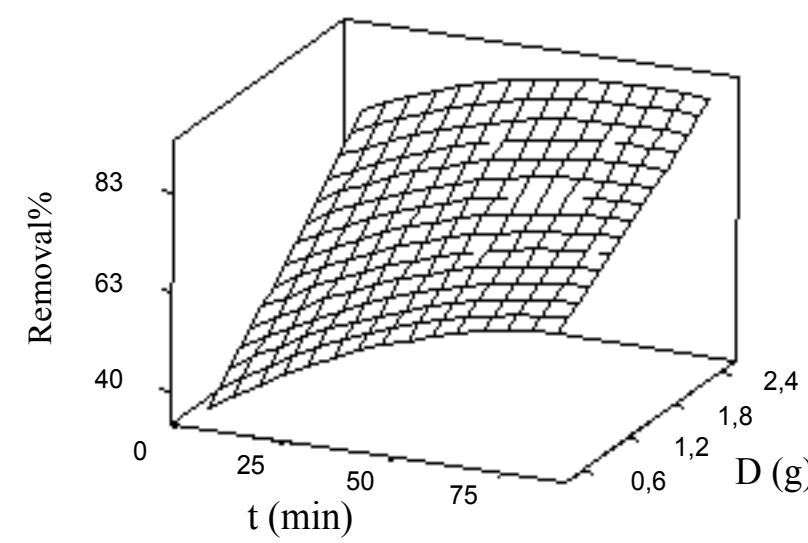

Figure 6: Response Surface of the Percentage Sorption of 2-CP ions versus time and dosage of Fe powder. 
Citation: Daraei H, Kamali H (2014) Experimental Design and Response Surface Modeling for Optimization of 2-Chlorophenol Removal from Water by Nanoscale Iron and Fe Powder. J Environ Anal Toxicol 4: 228. doi: 10.4172/2161-0525.1000228

by ad $\neg$ sorption or complex formation. Dechlorination process is demolition and forma $\neg$ tion of some intermediate compounds. Also, precipitation is consisted of insoluble compounds or removal of the contaminant ions via Trapping in the precipitates or on the ZVI surface $[30,31]$. Nano iron particle due to their high specific surface and high reactivity has an immense capability of sorption pollutants. The $\mathrm{Fe}$ ions of and 2-CP ions would supplant when Fe particles dripped into the liquid. Then, the Fe ions distributed into the solution. Thereafter, molecules of contaminant was adsorbed on the reactive surface of $\mathrm{Fe}$ particles and reacted with these particles. Therefore, with iron particles increase dosage, the active, adsorptive and reactive sorbent sites increased, thus led to the acceleration of the oxidation of 2-CP [32].

\section{Acknowledgement}

The authors are most grateful to the laboratory staff of the Department of Environmental Health Engineering, School of Public Health, Alborz University of Medical Sciences, for the financial support and their collaboration in this research.

\section{References}

1. Daraei H, Mittal A, Noorisepehr M, Daraei F (2013) Kinetic and equilibrium studies of adsorptive removal of phenol onto eggshell waste. Environ Sci Pollut Res Int 20: 4603-4611.

2. Matafonova G, Philippova N, Batoev V (2010) The Effect of Wavelength and $\mathrm{pH}$ on the Direct Photolysis of Chlorophenols by Ultraviolet Excilamps. Engg Lett 19: 20.

3. Rubín E, Rodríguez P, Herrero R, Manuel E, Vicente SD (2006) Biosorption of phenolic compounds by the brown alga Sargassum muticum. J Chem Tech Biotech 81: 1093-1099.

4. Koumanova B, Peeva-Antova P, Yaneva Z (2005) Adsorption of 4-chloropheno from aqueous solutions on activated carbon-kinetic stud. J Uni Chem Tech Metal 40: 213-218.

5. Yapar S, Klahre P, Klump E (2004) Hydrotalcite as a Potential Sorbent for the Removal of 2,4-Dichlorophenol. Turkish J Eng Env Sci 28: 41-48.

6. Jing-jing X, Min-dong C, De-gang F (2012) Preparation of bismuth oxide/ titania composite particles and their photocatalytic activity to degradation of 4-chlorophenol. Trans Nonferrous Met Soc China 1: 340-345.

7. Ling X, Li J, Zhu W, Zhu Y, Sun X, et al. (2012) Synthesis of nanoscale zerovalent iron/ordered mesoporous carbon for adsorption and synergistic reduction of nitrobenzene. Chemosphere 87: 655-660.

8. Chen J, Xiu Z, Lowry GV, Alvarez PJ (2011) Effect of natural organic matter on toxicity and reactivity of nano-scale zero-valent iron. Water Res 45: 1995-2001.

9. Fang YX, Al-Abed SR (2008) Dechlorination kinetics of monochlorobiphenyls by Fe/Pd: effects of solvent, temperature, and PCB concentration. Appl Catal B: Environ 78: 371-380

10. Jiao YL, Qiu CC, Huang LH, Wu KX, Ma HY, et al. (2009) Reductive dechlorination of carbon tetrachloride by zero-valent iron and related iron corrosion. Appl Catal B: Environ 91: 434-440.

11. Kassaee MZ, Motamedi E, Mikhak A, Rahnemai A (2011) Nitrate removal from water using iron nanoparticles produced by arc discharge vs. reduction. Chem Eng J 166: 490-495.

12. Kanel SR, Manning B, Charlet L, Choi H (2005) Removal of arsenic(III) from groundwater by nanoscale zero-valent iron. Environ Sci Technol 39: 1291-1298.

13. Gotpagar JK, Grulke EA, Bhattacharyya D (1998) Reductive dehalogenation of trichloroethylene: kinetic models and experimental verification. J Hazard Mater 62: $243-264$.

14. Wang CB, Zhang WX (1997) Synthesizing nanoscale iron particles for rapid and complete dechlorination of TCE and PCBs. Environ Sci Technol 31: 21542156.

15. Lu AH, Salabas EL, Schüth F (2007) Magnetic nanoparticles: synthesis, protection, functionalization, and application. Angew Chem Int Ed Engl 46: 1222-1244.

16. Xu L, Wang J (2011) A heterogeneous Fenton-like system with nanoparticulate zero-valent iron for removal of 4-chloro-3-methyl phenol. J Hazard Mater 186 256-264.
17. Daraei H, Mittal A, Mittal J, Kamali H (2013) Optimization of $\mathrm{Cr}(\mathrm{VI})$ removal onto biosorbent eggshell membrane: experimental \& theoretical approaches. Des Water 52: 7-9.

18. Zhang WH, Quan X, Zhang ZY (2007) Catalytic reductive dechlorination of p-chlorophenol in water using Ni/Fe nanoscale particles. J Environ Sci (China) 19: 362-366

19. Kamali H, Ghaziaskar HS (2010) Pressurized hot water extraction of benzoic acid and phthalic anhydride from petrochemical wastes using a modified supercritical fluid extractor and a central composite design for optimization. $J$ Super Flu 54: 16-21.

20. Babuponnusami A, Muthukumar K (2012) Removal of phenol by heterogenous photo electro Fenton-like process using nano-zero valent iron. Sep Purif Tech 98: 130-135.

21. Hamad BK, Noor AMD, Rahim AA (2011) Removal of 4-Chloro-2-Methoxyphenol from Aqueous Solution by Adsorption to Oil Palm Shell Activated Carbon Activated with K2CO3. J Physic Sci 22: 39-55

22. Wang JL, Liu GH, Zhang XR (2005) Recent developments of nanomaterials as sorbents. Chin J Anal Chem 33: 1787-1793.

23. Rasheed QJ, Pandian K, Muthukumar K (2011) Treatment of petroleum refinery wastewater by ultrasound-dispersed nanoscale zero-valent iron particles. Ultrason Sonochem 18: 1138-1142.

24. Liu L, Chen F, Yang F, Chen Y, Crittenden J (2012) Photocatalytic degradation of 2,4-dichlorophenol using nanoscale Fe/TiO2. Chem Eng J 181: 189-195.

25. Shu HY, Chang MC, Yu HH, Chen WH (2007) Reduction of an azo dye acid black 24 solution using synthesized nanoscale zerovalent iron particles. J Colloid Interface Sci 314: 89-97.

26. Engin B, Lokman U, Deniz T, Erkut $Y$, Igor $Y$, et al. (2007) Poly(acrylamideallyl glycidyl ether) Cryogel as a Novel Stationary Phase for Chlorophenol Adsorption. Hacettepe J Biol Chem 35: 219-23.

27. Konstantina T, Elpida P, Nikolaos PN (2007) Modeling of arsenic immobilization by zero valent iron. Eur J Soil Biol 4: 356-367.

28. Bang S, Johnson MD, Korfiatis GP, Meng X (2005) Chemical reactions between arsenic and zero-valent iron in water. Water Res 39: 763-770.

29. Rong C, JianLong W, WeiXian Z (2007) Reductive dechlorination of 2,4-dichlorophenol using nanoscale Fe0: influencing factors and possible mechanism. Sci China Ser B-Chem 50: 574-579.

30. Gunawardana B, Singha N, Swedlund P (2011) Degradation of Chlorinated Phenols by Zero Valent Iron and Bimetals of Iron: A Review. Environ Eng Res 16: 187-203.

31. Noubactep $C$ (2008) A critical review on the process of contaminant removal in $\mathrm{Fe} 0-\mathrm{H} 2 \mathrm{O}$ systems. Environ Technol 29: 909-920.

32. Zhang WH, Quan X, Zhang ZY (2007) Catalytic reductive dechlorination of p-chlorophenol in water using Ni/Fe nanoscale particles. J Environ Sci (China) 19: $362-366$ 